\title{
Does locomotor training improve pulmonary function in patients with spinal cord injury?
}

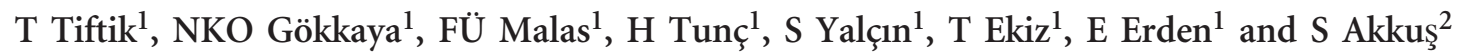

Objectives: The aim of this study was to compare the effects of a locomotor training (LT) combined rehabilitation program with a rehabilitation-only program on pulmonary function in spinal cord injury $(\mathrm{SCl})$ patients by investigating spirometric analyses of the patients.

Setting: Rehabilitation center in Ankara, Turkey.

Methods: Fifty-two patients (40 male, 12 female) with $\mathrm{SCl}$ enrolled in the study. The subjects were divided into two groups: the first group (group $A$ ) received both $L T$ and a rehabilitation program and the second group (group B) received only the rehabilitation program for 4 weeks. The LT program was prescribed as three 30-min sessions per week. Pulmonary function was evaluated spirometrically in both groups before and after the rehabilitation program.

Results: The spirometric values of the SCl patients, including forced vital capacity, forced expiratory volume in 1 second, forced expiratory flow rate and vital capacity (VC) and VC\%, increased significantly with LT in the first group (all $P<0.05$ ). Maximum voluntary ventilation values increased significantly in both groups (both $P<0.05$ ).

Conclusion: These findings suggest that LT is effective for improving pulmonary function in SCl patients. We also highlight the useful effects of LT, which are likely the result of erect posture, gait and neuroplastic changes that prevent potential complications in SCI patients.

Spinal Cord (2015) 53, 467-470; doi:10.1038/sc.2014.251; published online 17 February 2015

\section{INTRODUCTION}

Patients with spinal cord injury (SCI) experience a decrease in lung volume because of alterations in inspiratory and expiratory muscle function. Decreased chest wall and lung compliance, increased abdominal wall compliance and rib cage stiffness with paradoxical chest wall movements also contribute to breathing difficulties. ${ }^{1}$ Expiratory muscle function weakness can result in ineffective cough and a tendency toward mucus retention. Patients with cervical SCI also demonstrate heightened vagal activity, with increased secretions, bronchospasms and pulmonary edema. ${ }^{2}$ As a result, pulmonary complications have become the main cause of morbidity and mortality in SCI patients. ${ }^{1,3}$ Locomotor training (LT) in the form of body weight supported treadmill training (BWSTT) has become part of the rehabilitation program of SCI patients. Although most studies have focused on the effects of LT on the functional walking ability of patients with SCI, it also has many positive effects as a whole-body exercise procedure, such as on cardiopulmonary function, body composition and quality of life. ${ }^{4,5}$

Until recently, however, the effects of LT on the respiratory system have received little attention. Soyupek et al. ${ }^{5}$ investigated the heart rate, blood pressure and resting pulmonary function parameters at baseline and after BWSTT of eight subjects (two female, six male) with incomplete SCI. Terson de Paleville et al. ${ }^{6}$ compared eight patients with chronic SCI and 14 non-injured subjects. Sherman et al. ${ }^{7}$ presented a cervical SCI case in whom BWSTT resulted in reduced ventilatory demand and promoted locomotor-respiratory coupling during walking. However, none of those studies compared the effects of LT and a conventional rehabilitation program on pulmonary function. Therefore, our aim was to compare the effects of a combined LT and rehabilitation program with the effects of a rehabilitation-only program on pulmonary function in SCI patients by investigating the spirometric analyses of the patients. We hypothesized that LT would have a greater therapeutic effect on the pulmonary function of SCI patients as observed with pulmonary function tests.

\section{MATERIALS AND METHODS}

Participants

Fifty-two patients (40 male, 12 female) with SCI who were admitted to an inpatient rehabilitation program were enrolled in this study. Patients with concomitant brain injury, joint limitations or severe spasticity (Modified Ashworth Scale grades 3 and 4) and patients who were not cooperative were excluded. None of the patients had a previous history of pulmonary disease. The study protocol was approved by the local Medical Ethics Committee. Each patient provided informed consent to participate in the study.

\section{Study design}

This study was carried out prospectively. The subjects were divided into two groups: the LT group (group A; 19 males and seven females) and the control group (group B; 21 males and five females). Although the patients in group A received both LT and rehabilitation programs, the patients in group B received only the rehabilitation program. The conventional rehabilitation program

\footnotetext{
${ }^{1}$ Ankara Physical Medicine and Rehabilitation Training and Research Hospital, Department of Physical Medicine and Rehabilitation, Ankara, Turkey and ${ }^{2}$ Yıldırım Beyazit University Medical School, Department of Physical Medicine and Rehabilitation, Ankara, Turkey

Correspondence: Dr T Tiftik, Physical Medicine and Rehabilitation, Ankara Physical Medicine and Rehabilitation Education and Research Hospital, Sinhiye, Ankara 06410, Turkey.

E-mail: drttiftik@gmail.com

Received 9 June 2014; revised 25 December 2014; accepted 29 December 2014; published online 17 February 2015
} 
included a range of motion/stretching exercises; balance, endurance and coordination exercises; gait training with orthoses; and occupational therapy.

\section{Data collection-clinical assessment}

The demographic and clinical features of the patients were recorded. Injury severity was classified according to the American Spinal Injury Association Impairment Scale (AIS). ${ }^{8}$ The Functional Independence Measure motor score was used to assess functional ability. Spasticity was measured by using a modified Ashworth Scale. Pulmonary function parameters were obtained with spirometry.

\section{Locomotor training}

The locomotor training program was prescribed as three 30 -min sessions per week for 4 weeks. Before the training session, the subjects were fitted with a harness and body weight support system (Hocoma AG, Switzerland), supporting the trunk and pelvis over a treadmill and supporting the legs with cuffs. Treadmill speed was initially set as low as $1.0 \mathrm{~km} \mathrm{~h}^{-1}$ and increased by the therapist up to $1.5 \mathrm{~km} \mathrm{~h}^{-1}$ as tolerated by the subject.

\section{Pulmonary function test}

Resting pulmonary function parameters, including forced vital capacity (FVC), forced expiratory volume in 1 second (FEV1), forced expiratory flow rate 25-75\% (FEF 25-75\%), peak expiratory flow rate (PEF), vital capacity (VC), the ratio of FEV1 to FVC (FEV1/FVC) and maximum voluntary ventilation (MVV), were assessed spirometrically (Spirolab II; MIR, Italy) by the same person. Spirometry testing was performed with the patient in the seated position. Instructions were given and maneuvers were demonstrated for the participants before testing. Three acceptable spirograms were obtained, and the best result was used. The measurements were taken according to American Thoracic Society/European Respiratory Society, 2002 standards for acceptability and reproducibility. ${ }^{9}$ The spirometry device calculates predictive values for every patient, taking into account the patient's age, gender, race, weight and height. We considered spirometric values that reached at least $80 \%$ of the predicted values to be normal. The respiratory functional parameters of both groups were measured by spirometry before and after the rehabilitation program.

\section{Statistical analysis}

SPSS software version 15.0 (SPSS, Chicago, IL, USA) was used in the evaluation of the data; $P<0.05$ was considered statistically significant. Descriptive statistics were performed for all variables measured. The demographic and clinical data of the two groups were compared with the Mann-Whitney $U$-test or Student's $t$-test where appropriate. A $\chi^{2}$-test was used to analyze differences between the groups for categorical variables. A paired $t$-test or McNemar's test was used for within-group comparisons and subgroup analyses.

\section{RESULTS}

Characteristics of the 52 study subjects are shown in Table 1. The mean age of the patients was $31.2 \pm 12.7$ years in group A (LT group) and $35.6 \pm 15.0$ years in group B (control group) $(P=0.259)$. Group A included 19 male and 7 female SCI patients ( 7 cervical, 6 thoracic and 13 lumbosacral injuries) and group B included 21 male and 5 female SCI patients (10 cervical, 9 thoracic and 7 lumbosacral injuries). Time since injury was $10.6 \pm 13.5$ months in group A and $14.5 \pm 12.5$ months in group B $(P=0.291)$. There were no significant differences in age, body mass index, gender, smoking or time since injury between the groups. Distribution of the injury levels of the groups is shown in Table 2 .

The spirometric values of the SCI patients are provided in Table 3. Although the initial spirometric values of group B were lower compared with those of group A for all parameters, the differences were not statistically significant. After treatment, FVC, FEV1, FEF 2575 and $\mathrm{VC}$ and $\mathrm{VC} \%$ values increased significantly only in group A
Table 1 Characteristics of the study subjects

\begin{tabular}{|c|c|c|c|}
\hline Variable & Group A & Group B & P-value \\
\hline Age (years) & $31.2 \pm 12.7$ & $35.6 \pm 15.0$ & 0.259 \\
\hline $\mathrm{BMI}$ & $34.3 \pm 24.4$ & $30.11 \pm 23.5$ & 0.401 \\
\hline Gender (M/F) & $19 / 7$ & $21 / 5$ & 0.510 \\
\hline Smoking (yes/no) & $8 / 18$ & $7 / 19$ & 0.621 \\
\hline Time since injury (months) & $10.6 \pm 13.5$ & $14.5 \pm 12.5$ & 0.291 \\
\hline FIM & $46.7 \pm 19.7$ & $51.2 \pm 13.2$ & 0.324 \\
\hline \multicolumn{4}{|l|}{ Level of injury, $n(\%)$} \\
\hline $\mathrm{C} 1-\mathrm{C} 8$ & 7 (26.9) & $10(38.5)$ & \\
\hline $\mathrm{T} 1-\mathrm{T} 12$ & $6(23.1)$ & $9(34.6)$ & \\
\hline L1-S4/5 & $13(50.0)$ & 7 (26.9) & \\
\hline \multicolumn{4}{|l|}{ Cause of $\mathrm{SCl}, n(\%)$} \\
\hline Traumatic & $25(96.2)$ & $19(73.1)$ & \\
\hline Non-traumatic ${ }^{a}$ & $1(3.8)$ & $7(29.9)$ & \\
\hline \multicolumn{4}{|l|}{ Completeness of injury, $n(\%)$} \\
\hline Complete (AIS A) & $8(30.8)$ & $10(38.5)$ & \\
\hline Incomplete (AIS B, C, D) & $18(69.2)$ & $16(61.5)$ & \\
\hline
\end{tabular}

Abbreviations: AIS, American Spinal Injury Association Impairment scale; BMI, body mass index; FIM, functional independence measurement; SCl, spinal cord injury. Values are given as mean \pm s.d., ratio, or $n(\%)$

aneoplasia, infection, iatrogenic, vascular.

Table 2 Injury level distribution in the groups

\begin{tabular}{|c|c|c|c|}
\hline AIS & Cervical (n) & Thoracic (n) & Lumbosacral (n) \\
\hline \multicolumn{4}{|l|}{$A$} \\
\hline LT & 2 & 4 & 2 \\
\hline$C G$ & 1 & 6 & 3 \\
\hline \multicolumn{4}{|l|}{$B$} \\
\hline $\mathrm{LT}$ & 2 & 1 & 4 \\
\hline CG & 2 & 2 & 0 \\
\hline \multicolumn{4}{|l|}{$C$} \\
\hline LT & 0 & 1 & 6 \\
\hline $\mathrm{CG}$ & 4 & 1 & 2 \\
\hline \multicolumn{4}{|l|}{$D$} \\
\hline LT & 3 & 0 & 1 \\
\hline CG & 3 & 0 & 2 \\
\hline Total $(n)$ & 17 & 15 & 20 \\
\hline
\end{tabular}

Abbreviations: CG, control group (group B); LT, locomotor training group (group A).

(all $P<0.05$ ); MVV values increased significantly in both groups (both $P<0.05$ ).

To evaluate subgroups, we grouped the patients according to the injury level (cervicothoracic vs lumbosacral) and injury severity (motor complete (AIS A-B) vs incomplete (AIS C-D) injury). We found statistically significant results showing VC and FVC improvement in group A for all injury levels and injury severities (Table 4). When we assessed the predictive spirometric values, we found improvement in some of the values after LT, although those did not reach statistical significance. 
Table 3 Spirometric values in $\mathrm{SCl}$ patients (mean \pm s.d.)

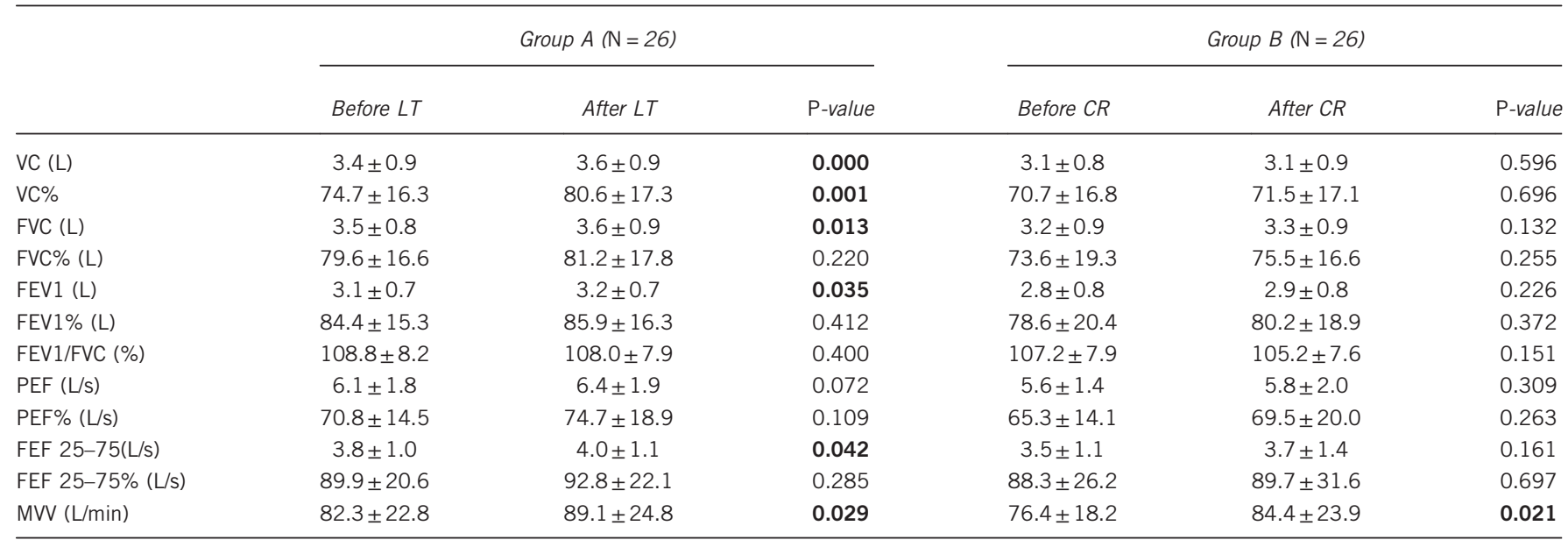

Abbreviations: CR, conventional rehabilitation program; FEV1, forced expiratory volume in one second; FEF25-75, forced expiratory flow rate; FVC, forced vital capacity; LT, locomotor training; MVV, maximum voluntary ventilation; PEF, peak expiratory flow rate; VC, vital capacity. Bold $P$-values indicate significance.

Table 4 Spirometric values in $\mathrm{SCl}$ patient subgroups (mean \pm s.d.)

\begin{tabular}{|c|c|c|c|c|c|c|c|c|}
\hline & $\mathrm{N}$ & Before $L T$ & After $L T$ & P-value & $\mathrm{N}$ & Before $C R$ & After $C R$ & P-value \\
\hline Cervicothoracic & 13 & $67.6 \pm 15.3$ & $74.3 \pm 17.6$ & 0.030 & 19 & $70.9 \pm 16.5$ & $70.9 \pm 17.2$ & 0.998 \\
\hline$>80(\%)$ & & 23.1 & 46.2 & 0.250 & & 26.3 & 26.3 & 1.000 \\
\hline Lumbosacral & 13 & $81.8 \pm 14.5$ & $86.9 \pm 15.2$ & 0.024 & 7 & $70.3 \pm 18.9$ & $73.1 \pm 18.1$ & 0.091 \\
\hline$>80(\%)$ & & 40.0 & 40.0 & 1.000 & & 21.4 & 28.6 & 1.000 \\
\hline AIS C-D & 11 & $78.3 \pm 17.9$ & $87.0 \pm 19.5$ & 0.019 & 12 & $69.8 \pm 16.9$ & $69.9 \pm 19.2$ & 0.974 \\
\hline$>80(\%)$ & & 63.6 & 81.8 & 0.500 & & 33.3 & 25.0 & 1.000 \\
\hline \multicolumn{9}{|l|}{ FVC\% } \\
\hline AIS A-B & 15 & $72.1 \pm 15.0$ & $75.9 \pm 14.4$ & 0.032 & 14 & $77.2 \pm 19.1$ & $77.6 \pm 15.4$ & 0.870 \\
\hline$>80(\%)$ & & 33.3 & 53.3 & 0.250 & & 35.7 & 42.9 & 1.000 \\
\hline AIS C-D & 11 & $78.3 \pm 17.9$ & $87.0 \pm 19.5$ & 0.019 & 12 & $69.5 \pm 19.4$ & $73.1 \pm 18.2$ & 0.129 \\
\hline$>80(\%)$ & & 81.8 & 81.8 & 1.000 & & 33.3 & 41.7 & 1.000 \\
\hline
\end{tabular}

Abbreviations: AIS, American Spinal Injury Association Impairment Scale; FVC, forced vital capacity; LT, locomotor training; VC, vital capacity.

Significant values are in bold.

\section{DISCUSSION}

In this study, we compared the effects of a combined LT rehabilitation program and a conventional rehabilitation program only on the pulmonary functions of SCI patients. Our results showed that LT had positive effects on VC and FVC values in SCI patients compared with the control group.

The effects of LT on pulmonary function have been mentioned previously in the literature. ${ }^{5-7}$ Soyupek et al. ${ }^{5}$ investigated the heart rate, blood pressure, resting pulmonary function parameters and psychological status (using the Beck Depression Inventory) of eight subjects (two females and six males) with incomplete SCI at baseline and after BWSTT. They found that undergoing BWSTT for 6 weeks had a positive effect on heart rate and limited effect on pulmonary function. Terson de Paleville et al. ${ }^{6}$ compared the eight patients with chronic SCI ( $25 \pm 12$ months post-injury) and 14 non-injured subjects and found that LT significantly improved pulmonary function in the individuals with chronic SCI. Sherman et al. ${ }^{7}$ presented a case with cervical SCI in which BWSTT resulted in reduced ventilatory demand and promoted locomotor-respiratory coupling during walking.

Our spirometric test results revealed that FVC, FEV1, FEF 25-75 and VC values increased significantly with LT in Group A $(P<0.05)$; there were no significant differences among these parameters in Group B. In subgroup analysis according to the level of injury and severity of injury, we found significant results showing improvement in the spirometric parameters, particularly VC and FVC, in the LT group. These findings suggest that LT had greater incremental effects on 
forced respiratory function and lung capacity compared with the conventional rehabilitation program.

Regulation of the respiratory system is known to be multifactorial. Blood-gas concentration changes, ${ }^{10}$ brainstem nucleus control ${ }^{11}$ and altered diaphragm and abdominal muscle activation by postural changes $^{12}$ are known to be effective. Volitional effort and effects of LT on respiratory function likely take an active role in respiratory regulation after SCI. In addition, a functional connection of the corticospinal tract fibers, from motor cortex to the spinal motor circuitry of the respiratory and accessory respiratory muscles, has also been shown. ${ }^{13-18}$ Furthermore, LT has been shown to enhance corticospinal connectivity to spinal motor circuitry in the leg muscles of chronic incomplete SCI patients. ${ }^{19}$ In a study by Harkema et al. ${ }^{20}$ specific motor tasks generated electromyographic activity in the trunk muscles and extremities, showing that LT provides intensive proprioceptive feedback to the spinal cord. Although different studies have reported the positive effects of $\mathrm{LT}$, the actual mechanism is not certain. In the subgroup analysis of this study, we found that the VC and FVC values of the SCI patients at all injury levels improved significantly. As such, it is apparent that all of the mechanisms mentioned are active during LT and LT might increase respiratory muscle activity, which could lead to neuroplastic changes.

In our study, although we found significant improvements in FVC, FEV1, FEF 25-75 and VC and VC\%, no significant differences in FVC $\%$, FEV1\%, PEF, PEF\% or FEF $25-75 \%$ were observed between the groups. The lack of significant changes in percentage values with the LT program might be due to the short training time. Longer periods of LT might result in increased values of all of the spirometric measurements. Normal or elevated FEV1/FVC values are predictors of restrictive pathologies, which is an expected pattern in SCI. In contrast, MVV values increased significantly in both groups, possibly due to the general exercise effect of the rehabilitation program.

The short duration of the LT program is one of the limitations of this study. Another limitation is that we did not include maximum expiratory and inspiratory pressure in our assessment. It would be a powerful evaluation parameter to show improvement of the respiratory muscles directly. In addition, the level of injury is known to affect pulmonary function tests in SCI patients, and the pulmonary function parameters of patients with more severe neurologic deficits associated with SCI are more severely impaired. ${ }^{21,22}$ In this study, the distribution of injury levels might have affected the results in favor of the LT group, as we had seven cervical level patients in the LT group and ten in the control group and six thoracic level patients in the LT group and nine in the control group. There were 13 lumbar-sacral level patients in the LT group and 7 in the control group. Furthermore, although our sample size was not very small, we believe that recruiting more individuals might sharpen the differences between groups as well.

\section{CONCLUSION}

Our findings show that 4 weeks of LT as a whole-body exercise procedure had positive effects on pulmonary function in SCI patients. LT supplies the active component and contains a level of training intensity that is crucial for respiratory improvement. In light of the relevant literature, LT supports an erect posture, and cortical and peripheral inputs for respiratory control can induce neuroplastic changes that contribute to respiration.

\section{DATA ARCHIVING}

There were no data to deposit.

\section{CONFLICT OF INTEREST}

The authors declare no conflict of interest.

1 Schilero GJ, Spungen AM, Bauman WA, Radulovic M, Lesser M. Pulmonary function and spinal cord injury. Respir Physiol Neurobiol 2009; 166: 129-141.

2 Galeiras Vazquez R, Rascado Sedes P, Mourelo Fariña M, Montoto Marques A, Ferreiro Velasco ME. Respiratory management in the patient with spinal cord injury. Biomed Res Int 2013; 2013: 168-757.

3 Postma K, Haisma JA, de Groot S, Hopman MT, Bergen MP, Stam HJ et al. Changes in pulmonary function during the early years after inpatient rehabilitation in persons with spinal cord injury: a prospective cohort study. Arch Phys Med Rehabil 2013; 94: 1540-1546.

4 Hicks A. Ginis K. Treadmill training after spinal cord injury: it's not just about the walking. J Rehabil Res Dev 2008; 45: 241-248.

5 Soyupek F, Savas S, Oztürk O, Ilgün E, Bircan A, Akkaya A. Effects of body weight supported treadmill training on cardiac and pulmonary functions in the patients with incomplete spinal cord injury. J Back Musculoskelet Rehabil 2009; 22: 213-218.

6 Terson de Paleville D, McKay W, Aslan S, Folz R, Sayenko D, Ovechkin A. Locomotor step training with body weight support improves respiratory motor function in individuals with chronic spinal cord injury. Respir Physiol Neurobiol 2013; 189 . 491-497.

7 Sherman MF, Lam T, Sheel AW. Locomotor-respiratory synchronization after body weight supported treadmill training in incomplete tetraplegia: a case report. Spinal Cord 2009; 47: 896-898.

8 Kirshblum S, Waring W, Biering-Sorensen F, Burns S, Johansen M, Schmidt-Read M et al. Reference for the 2011 revision of the International Standards for Neurological Classification of Spinal Cord Injury. J Spinal Cord Med 201134 547-554.

9 American Thoracic Society/European Respiratory Society. ATS/ERS Statement on respiratory muscle testing. Am J Respir Crit Care Med 2002; 166: 518-624.

10 Saupe K, Smith C, Henderson K, Dempsey J. Respiratory muscle recruitment during selective central and peripheral chemoreceptor stimulation in awake dogs. J Physio 1992; 448: 613-631.

11 Yates B, Jakus J, Miller A. Vestibular effects on respiratory outflow in the decerebrate cat. Brain Res 1993; 629: 209-217.

12 Cotter L, Arendt H, Jasko J, Sprando C, Cass S, Yates B. Effects of postural changes and vestibular lesions on diaphragm and rectus abdominis activity in awake cats. J Appl Physiol 2001; 91: 137-144.

13 Davey N, Murphy K, Maskill D, Guz A, Ellaway P. Site of facilitation of diaphragm EMG to corticospinal stimulation during inspiration. Respir Physiol 1996; 106: 127-135.

14 Ellaway P, Catley M, Davey N, Kuppuswamy A, Strutton P, Frankel H et al. Review of physiological motor outcome measures in spinal cord injury using transcranial magnetic stimulation and spinal reflexes. J Rehabil Res Dev 2007; 44: 69-76.

15 Bawa P, Hamm J, Dhillon P, Gross P. Bilateral responses of upper limb muscles to transcranial magnetic stimulation in human subjects. Exp Brain Res 2004; 158 385-390.

16 Tsao H, Galea M, Hodges P. Concurrent excitation of the opposite motor cortex during transcranial magnetic stimulation to activate the abdominal muscles. J Neurosci Methods 2008; 171: 132-139.

17 Strutton P, Beith I, Theodorou S, Catley M, McGregor A, Davey N. Corticospinal activation of internal oblique muscles has a strong ipsilateral component and can be lateralised in man. Exp Brain Res 2004; 158: 474-479.

18 Nowicky A, McGregor A, Davey N. Corticospinal control of human erector spinae muscles. Motor Control 2001; 5: 270-280.

19 Thomas S, Gorassini M. Increases in corticospinal tract function by treadmill training after incomplete spinal cord injury. J Neurophysiol 2005; 94 : 2844-2855.

20 Harkema SJ. Plasticity of interneuronal networks of the functionally isolated human spinal cord. Brain Res Rev 2008; 57: 255-264.

21 Linn W, Spungen A, Gong HJ, Adkins R, Bauman W, Waters R. Forced vital capacity in two large outpatient populations with chronic spinal cord injury. Spinal Cord 2001; 39: 263-268.

22 Stepp E, Brown R, Tun C, Gagnon D, Jain N, Garshick E. Determinants of lung volumes in chronic spinal cord injury. Arch Phys Med Rehabil 2008; 89. 1499-1506. 